\title{
A Study on the Impact of Development of Vocational Education on Economic Growth in Chongqing
}

\author{
Shuaijin Huang \\ School of Economics \\ Chongqing Technology and Business University \\ Chongqing, China
}

\author{
Chengjie Liu \\ School of Economics \\ Chongqing Technology and Business University \\ Chongqing, China
}

\begin{abstract}
This paper studies the long-term and short-term impact of vocational education on economic growth in Chongqing by using the data of vocational education investment and GDP time series since Chongqing became municipality and constructing ECM model. The results show that vocational education has significant impact on the economic growth in Chongqing, and its long-term impact is more significant than the fluctuant impact of short-term, and the promotion effect of vocational education on economic growth is relatively stable. Finally, countermeasures and suggestions for development of vocational education in Chongqing is put forward from the three aspects including increasing vocational education investment, reasonable adjustment of vocational education industry layout and location layout.
\end{abstract}

Keywords-vocational education; economic growth; promotion effect; ECM model

\section{INTRODUCTION}

In 2016, Chongqing takes the lead in economic growth in China with the economic growth rate of $10.7 \%$, becoming the only region that maintains rapid economic growth under the new normal of economic growth in China, so it is necessary to explore the deep reasons behind its rapid economic growth. According to the classical Cobb-Douglas production function $\mathrm{Y}=\mathrm{AF}(\mathrm{K}, \mathrm{L})$ we can see that economic growth is determined by capital investment, labor input and technical level. The prevailing situation in China is that the return on capital investment in the real economy has fallen to a relatively low level, while the overall technical level of economy has not improved significantly, so in this case, Chongqing's leading position in economic growth in China can only be explained by labor force input and the human capital attached to the labor force.

At present, disconnection between higher education in China and real industry demand is more serious, and vocational education cultivates professionals based on the characteristics and needs of various industries, which plays an important role in the adjustment of the current structural contradiction between labor supply and demand. In recent years, Chongqing has vigorously developed vocational

Fund Project: Social Science Fund Project in Chongqing "Study on strengthening the integration of higher vocational and technical education and economic development in Chongqing" (2012YBJJ038), host: Liu Youxin. education. Up to the first half of 2017, there are totally 254 vocational schools in Chongqing, with about a total of 736,000 students at school. In the past five years, vocational education in Chongqing has provided a total of 1.1 million people to society. In professional setting, secondary vocational schools totally set up 18 major categories and 168 majors, and higher vocational colleges set up 19 major categories and 312 majors in total. The city has basically formed the vocational education system that matches the regional economy and industrial transformation and upgrading. The rapid development of vocational education plays an important role in the accumulation of human capital in Chongqing, which not only adapts to the needs of industrial restructuring, but also has significant meaning to improving the employment of residents, increasing income and economic growth. On this basis, this paper intends to study the relationship between economic growth and the development of vocational education in Chongqing through empirical analysis.

\section{LITERATURE REVIEW}

\section{A. Theoretical Study}

1) Theoretical basis: The theoretical basis of the relationship between vocational education and economic growth can be traced back to the theory of human capital founded by Schultz and Becker in the 1960s. The theory emphasizes that human resources are the most important resource of all resources and in economic growth, the role of human capital is greater than material capital. The core issue of human capital is to improve the population quality, and education investment is the key to improve human capital as well as the most basic means to improve the population quality. Therefore, issue of investment in human capital can be regarded as the issue of education investment. Schultz also suggests that investment in human capital includes education, on-the-job training, improving health level and labor migration. In several ways of investment in human capital, education investment is the most important one [3] According to study of Feng Xiao et al. (2012), the marginal output effect of investment in human capital in China is higher than that of investment in physical capital and the marginal output contribution of vocational education is 
higher than that of higher education [4]. It can be seen that the role of education or vocational education in economic growth has always been the focus of scholars' research.

2) The approach of development of vocational education promoting the economic growth: After sorting out the previous theoretical researches, it can be found that the approach of vocational education promoting regional economic growth can be divided into the following three kinds: First, to optimize the labor structure and improve labor productivity. Vocational education can provide a large number of technical and professional talents who can quickly adapt to a variety of technical and professional work needs for society, which can improve the overall labor proficiency in the region, thereby enhancing labor productivity. Second, to promote technological innovation and improve production efficiency. The labor forces who have received vocational education generally have strong professional quality in certain fields. In the practice process, it is easier to innovate in specific technology, increase the technical content of regional economic development and improve the production efficiency. Third, it is conducive to optimizing the regional industrial structure and giving birth to new industry formats. Vocational education firstly prepares for regional industrial structure from the human capital structure; secondly, vocational education promotes the regional technological innovation, and provides the technical support for regional industrial structure adjustment and generation of new industry formats.

\section{B. Empirical Study}

1) Foreign research: Foreign research on the relationship between education and economic growth starts earlier. Denison (1967) measures that the contribution of human capital to economic growth in the United States between 1929 and 1957 is 23.83\% [6]. Schultz quantifies the average yield rate of education investment at all levels in the United States to economic growth from 1929 to 1957 is $17 \%$, and then concludes that the yield of education income growth accounted for $33 \%$ of national income growth. Mincer (1974) uses the benefit of human capital equation to count the contribution of education in many countries to economic growth and finds a $5 \%$ to $15 \%$ increase in benefit for every 1 year increase in education years. Barrow (1992) concludes that there is a positive correlation between economic growth rate and the enrollment rate and the correlation coefficient is 0.73 through regression analysis of the relationship between enrollment rates and per capita GDP growth rates in 98 countries between 1960 and 1985 . At the same time, there are many studies on the relationship between vocational education and economic growth. Chung Y (1986) comes to the conclusion that the role of vocational education is less than that of general middle school education in the context of rapid industrialization and economic growth through a review of the history of economic development and the development of vocational education in Hong Kong. Vaughan R J (1991) argues that the obstacle to US economic growth is not the lack of material resources and the growth of the population, but the lack of professional skills and creativity. Therefore, vocational education should be developed to improve this situation [9]. David and Francis (1996) study the relationship between vocational education and economic growth from a global perspective, and concludes that the development of vocational education could promote the improvement of labor productivity to promote economic growth [10]. Self S and Grabowski R (2003) find that primary education and economy in Japan before and after World War II have causal relation and that secondary and higher education have played a significant role in promoting economic growth in Japan through the study of the relationship between education of various levels in Japan and economic growth before and after World War II in Japan, but they find that vocational education has no direct impact on economic growth in Japan both before and after the war[11]. Mupimpila C and Narayana N (2009) find that there is a positive relationship of mutual promotion between local economic growth and vocational education and skills training through a case study of Botswana [12]. Anders Nilsson (2010) argues that the development of vocational education not only contributes to economic growth, but also helps to consolidate social integration. Through literature research, he believes that vocational education and training can significantly increase productivity at the corporate level, while the effect at the overall economic level cannot be determined certain [13]. Đuric', I et al. (2013) argues that the development of secondary vocational education is a proper practice in adapting to educational reform and economic change in the context of rapid socio-political and economic change in Serbia through combing the literature [14]. HK Pillay and A Ninan (2014) hold that vocational education will play an important role in India's future economic development by analyzing the economic downturn in India and forecasting economic growth, based on analyzing the role of vocational education in India.

2) Domestic research: There are a large amount of studies on the relationship between vocational education and economic growth in China, which mainly use the method of Dennison's Factor Analysis and regression analysis based on difference in education years. Fu Zhiming and Xu Xiaoyan (2005) use the method of Dennison's Factor Analysis to calculate the contribution rate of vocational education in China to economic growth is $51.69 \%$ [16]. Based on the method of Dennison's Factor Analysis, Hang Yongbao calculates the contribution rate of Chinese education to economic growth. The contribution rate of Chinese secondary and higher vocational education to economic growth is $1.859 \%$ and $4.038 \%$ respectively in 1993-2004. The contribution of vocational education to economic growth is much higher than that of other [17]. Yang Yi and Tan Jiezhong (2010) replace the "weight distribution 
method" in the calculating method of education contribution rate of Dennison by the "incremental method of index" and uses the improved Dennison method to measure the contribution rate of vocational education to economic growth in China in 2001-2008. [18]. Based on Dennison's educational economics method, Liu Weiwei and An Heping taking Hebei Province as an example, come to the conclusion that contribution of vocational education to economy in Hebei is the greatest by comparing the contribution of education of different levels to economic growth [1] 115-117. Liu Xinming et al. (2011) and Tang Xiaochu (2014) use the Denison method to measure the contribution rate of higher vocational education to economic growth in in Zhejiang Province from1990 to 2009 and Guangdong Province from 1990 to 2009 respectively [5,19]. Guo Xinhua and Yu Xiaoyue (2010) calculate that the contribution of secondary vocational education in China's to economic growth rate is $18.7 \%$ through the time series data[20]. Wang Peijun and Wang Liping (2011) conclude that there is a positive correlation between the development of vocational education and economic growth in China by using the panel data model. [21] Wang Lei (2011) works out the average contribution rate of vocational education in each provinces in China to economic growth is $0.23 \%$ based on panel data, and decomposes this contribution rate to obtain the result that contribution of promoting human capital accumulation to economic growth is $0.05 \%$ and that of promoting employment to economic growth is $0.18 \%$. [22] Zhou Hong et al. (2012) selectes the provincial panel data in China in 2003-2008 to build the regression model, and analyzes the impact of secondary vocational education on economic growth based on the production function model, [23]. Wang Haiyan and Shen Youlu (2012) introduce educational variables into the Cobb-Douglas production function and analyzed the relationship between secondary vocational education and economy in western China based on the time series data from 1990 to 2009 [24]. Yang Yong et al. (2016) study the relationship between the scale of higher vocational education in China and the economy by constructing an error correction model [25]. Li Changhui et al. (2008) and Hu Jiangxia et al. (2013) use the gray relational theory to analyze the correlation between vocational education in Chongqing and economic development and its positive impact on economic development. [26] [27] Xu Ling (2013) uses the elastic coefficient method to analyze the relationship between the change of the scale of higher vocational education in China and the economic growth from 1992 to 2010, and points out that the effect of higher vocational education on economic growth is higher than that of higher education, and the relationship between higher vocational education and economic growth presents a phased feature. [28]

3) Literature review: In summary, studies made by domestic and foreign scholars on the relationship between vocational education and economic growth are very sufficient. However, most predecessors study the impact of vocational education on economic growth from the national level, while less from the regional level; secondly, when making time series modeling, the model is too rough without necessary model testing and selection. Based on this, this study aims to establish the error correction model of the impact of vocational education on economic growth in Chongqing to study the relationship between vocational education and economic growth in Chongqing through examination and comparison and selecting the model form accurately.

\section{EMPIRICAL ANALYSIS}

\section{A. Data Selection and Processing}

This study plans to select the expenditure data of vocational education in Chongqing to characterize the development of vocational education in Chongqing (represented by VE) and select the regional GDP data of Chongqing to represent the economic growth of Chongqing (represented by GDP). The data period is from 1998 to 2015 , with a total data of 18 years, and data are respectively from the "Yearbook of Chongqing Education Fund statistics" and "Chongqing Statistical Yearbook" over the years.

To study the relationship between vocational education and economic growth in Chongqing, we must first define the scope of vocational education. As the vocational education in Chongqing starts late and has been in the development and change, its scope is constantly changing. According to the arrangement of education expenditure of educational institutions at all levels and of all kinds in the "Yearbook of Chongqing Education Fund statistics" over the years, it can be found that since Chongqing became the municipality to 2004, scope of vocational education in Chongqing includes secondary specialized schools, technical schools and vocational middle schools; in 2005 and 2006, it includes vocational colleges, secondary professional schools, technical schools and vocational middle schools; from 2007 till now, scope of Chongqing vocational education includes vocational colleges and secondary vocational schools.

It is unscientific to simply study the relationship between expenditure on vocational education and economic growth in Chongqing, because some of the expenditure on vocational education expenditure over the years will form fixed assets, which will play a role in economic growth for a long period of time. Therefore, we cannot simply use the flow indicator of expenditure on vocational education over the years to study the relationship between vocational education and economic growth, but we must take into account the impact of the formation of fixed assets of the expenditure on vocational education on economic growth. The three parts of expenditure including equipment purchasing costs, repair costs and infrastructure expenses in the expenditure on vocational education over the years will form the fixed assets and thus have a long-term impact on economic growth. Therefore, the long-term impact of these three parts needs to be observed. We intend to use the perpetual inventory method to make inventory for the formation of fixed assets 
of vocational education since Chongqing became the municipality. The equation is $\mathrm{K}_{\mathrm{t}}=\mathrm{It}+\left(1-\delta_{\mathrm{t}}\right) \mathrm{K}_{\mathrm{t}-1}$, of which $\mathrm{K}_{\mathrm{t}}$ and $K_{t-1}$ are the stock of fixed assets in t period and $t-1$ period respectively, It is the investment on fixed assets in $t$ period, and $\delta_{\mathrm{t}}$ is the Reset rate. The investment of fixed assets in vocational education of Chongqing in 1998 is regarded as the base fixed assets stock in base period. Based on the study of Hall and Jones (1999), the reset rate is set at $6 \%$ [28]. First of all, the author adjusts the investment in fixed assets of vocational education in Chongqing over the years by the fixed asset investment price index with 1998 as the base period, and then the takes inventory of investment in fixed assets of vocational education in Chongqing.

TABLE I. GDP IN 1998 - 2015 AND THE "ACTUAL INVESTMENT" OF VOCATIONAL EDUCATION FUNDING IN CHONGQING

\begin{tabular}{lllll}
\hline Year & $\begin{array}{c}\text { GDP (Ten } \\
\text { thousand yuan) }\end{array}$ & InGDP & $\begin{array}{c}\text { VE (Ten } \\
\text { thousand yuan) }\end{array}$ & In VE \\
\hline $\mathbf{1 9 9 8}$ & 16023800 & 16.5896 & 66462 & 11.1044 \\
$\mathbf{1 9 9 9}$ & 16749574 & 16.6339 & 92873 & 11.4390 \\
$\mathbf{2 0 0 0}$ & 18653154 & 16.7415 & 118212 & 11.6802 \\
$\mathbf{2 0 0 1}$ & 20244859 & 16.8234 & 133922 & 11.8050 \\
$\mathbf{2 0 0 2}$ & 22960213 & 16.9493 & 159233 & 11.9781 \\
$\mathbf{2 0 0 3}$ & 26122164 & 17.0783 & 170568 & 12.0469 \\
$\mathbf{2 0 0 4}$ & 29908884 & 17.2137 & 196037 & 12.1861 \\
$\mathbf{2 0 0 5}$ & 33905309 & 17.3391 & 257792 & 12.4599 \\
$\mathbf{2 0 0 6}$ & 37309800 & 17.4348 & 300755 & 12.6140 \\
$\mathbf{2 0 0 7}$ & 42650772 & 17.5686 & 424191 & 12.9579 \\
$\mathbf{2 0 0 8}$ & 50038312 & 17.7283 & 486653 & 13.0953 \\
$\mathbf{2 0 0 9}$ & 57315013 & 17.8641 & 580722 & 13.2720 \\
$\mathbf{2 0 1 0}$ & 67407141 & 18.0263 & 678336 & 13.4274 \\
$\mathbf{2 0 1 1}$ & 80859197 & 18.2082 & 837601 & 13.6383 \\
$\mathbf{2 0 1 2}$ & 89831008 & 18.3134 & 1074093 & 13.8870 \\
$\mathbf{2 0 1 3}$ & 98045318 & 18.4009 & 1300075 & 14.0779 \\
$\mathbf{2 0 1 4}$ & 107505533 & 18.4931 & 1395588 & 14.1488 \\
$\mathbf{2 0 1 5}$ & 117002524 & 18.5777 & 1535327 & 14.2443 \\
\hline
\end{tabular}

After deducting fixed assets investment in vocational education, "pure investment" mainly includes wage and welfare expenses and subsidies for individuals and families, so we use the CPI index with 1998 as the base period to adjust the part of data of "pure investment". Finally, "pure investment" data after adjustment of the price index is added to the stock of fixed assets of vocational education at the end of each calendar year after taking inventory to obtain the "actual investment" of educational fund of vocational education in Chongqing over the years. We use this "actual investment" to represent the development of vocational education in Chongqing (VE), to study its relationship with economic growth in Chongqing (GDP), and GDP is adjusted to constant prices by the CPI index with 1998 as the base period. In order to eliminate variance and reduce the impact of data fluctuations, we select the natural logarithm of VE and GDP to study. The processed data are shown in "Table I":

\section{B. Data Validation and Model Building}

This study intends to study the causal relationship and long-term equilibrium relationship between vocational education and economic growth through time series variables. The classical model of long-term equilibrium and short-term fluctuation relationship between two time series variables is the error correction model, so error correction model is selected to study the relationship between vocational education and economic growth in Chongqing.

When studying the relationship between the time series, the sequence should be stable. If the sequence is not stable, some of the statistics of regression parameters are not standard distribution, so the regression is called "spurious regression", and all the statistical tests will also lose efficacy. The time series of economic and social variables in reality are often non-stable because of the long span. Therefore, stable test should be made for the series before constructing the model with time series variables, to determine its stationarity and integration order.

1) Unit root test of sequence: Error correction model requires the relationship between relevant time series is the co-integration relationship, and the premise of existence of co-integration relationship is that the two time series are the integration of same order. Then the author firstly uses Eviews8.0 software to make stable test of ADF and PP on Sequence lnGDP and $\ln V E$. The model of the ADF test is as follows:

$$
\begin{array}{ll}
\Delta y_{t}=\eta y_{t-1}+\sum_{i=1}^{p-1} \beta_{i} \Delta y_{t-i}+u_{t} & t=1,2, \cdots, T \\
\Delta y_{t}=\eta y_{t-1}+\alpha+\sum_{i=1}^{p-1} \beta_{i} \Delta y_{t-i}+u_{t} & t=1,2, \cdots, T \\
\Delta y_{t}=\eta y_{t-1}+\alpha+\delta t+\sum_{i=1}^{p-1} \beta_{i} \Delta y_{t-i}+u_{t} t=1,2, \cdots, T
\end{array}
$$

Among them, $y_{t}$ is the sequence to be tested, $\alpha$ is a constant, $\mathrm{p}$ is the lag order, and $\mathrm{u}_{\mathrm{t}}$ is a random error term. Which model is selected for the test is judged by the line tendency line, and the lag order $\mathrm{p}$ is determined by the criteria of the minimum AIC and SC values [30] 167-168.

The original hypothesis of the test is: $\eta=0$, i.e., the roots of unity exist in the series; alternative hypothesis: $\eta \neq 0$, i.e. there is no root of unity in the series.

TABLE II. ADT TEST OF TIME SERIES INGDP AND INVE

\begin{tabular}{cllllll}
\hline Variables & $(\alpha, \delta, p)$ & ADF value & Critical value of 1\% & Critical value of 5\% & Critical value of 10\% & Conclusion \\
\hline $\boldsymbol{l n} \boldsymbol{G D P}$ & $(\alpha, \delta, 3)$ & -1.601 & -4.668 & -3.733 & -3.310 & non-stable series \\
$\boldsymbol{d} \boldsymbol{l n} \boldsymbol{G D P}$ & $(\alpha, 0,3)$ & -2.966 & -3.920 & -3.066 & -2.674 & stable series \\
$\boldsymbol{l} \boldsymbol{n} \boldsymbol{V} \boldsymbol{E}$ & $(\alpha, \delta, 3)$ & -2.949 & -4.728 & -3.760 & -3.325 & non-stable series \\
$\boldsymbol{d} \boldsymbol{l n} \boldsymbol{V} \boldsymbol{E}$ & $(\alpha, 0,3)$ & -3.228 & -4.058 & -3.120 & -2.701 & stable series \\
\hline
\end{tabular}

a. Note: "d" means the first difference, $(\alpha, \delta, p)$ represents the test form, $\alpha, \delta, p$ respectively represent the constant term, the trend item and the lag order, and the determination of the lag order is based on the minimum AIC and SC values, hereinafter the same. 
According to the results of ADF test in "Table II", the ADF statistic of sequence lnGDP and $\operatorname{lnVE}$ are greater than the critical value at the significance level of $10 \%$, so the logarithmic sequence of economic growth and the logarithmic sequence of vocational education are non-stable. The ADF values of sequence dlnGDP and dlnVE are less than the critical value at the significance level of $10 \%$ and $5 \%$ respectively, so the dlnGDP and dlnVE are stable series. That is to say, lnGDP and lnVE are both integration of order 1 , indicating that there may be co-integration between economic growth and investment in vocational education in Chongqing.

2) Co-integration test of series: Based on the results of the stable test of series, we make the co-integration test between series. Co-integration test is used to determine the equilibrium relationship between non-stable series, namely the stationarity of linear combinations of non-stable series. The significance of the co-integration test is to determine whether the variables with equilibrium relationship economically have a stable or balanced relationship in a statistical sense. The specific definition of co-integration is as follows:

The component sequences of k-dimensional vector time series $\mathbf{y}_{t}=\left(y_{1 t}, y_{2 t}, \cdots, y_{k t}\right)^{\prime}(t=1,2, \cdots, T)$ is called $\mathrm{d}, \mathrm{b}$ order co-integration, recorded as $\mathbf{y}_{t} \square C I(d, b)$, if it satisfies:

- $\mathbf{y}_{t} \square I(d)$, that means requiring every component of $\mathbf{y}_{t}$ is integration of order $\mathrm{d}$;

- There is a nonzero vector $\boldsymbol{\beta}$ to make $\boldsymbol{\beta}^{\prime} \mathbf{y}_{t} \square I(d-b), 0<b \leq d$.

The short name is co-integration, and vector $\boldsymbol{\beta}$ is also called co-integration vector. For the co-integration analysis, we need to pay attention to the following three points: First, the co-integration vector is not unique, but there may be k-1 linearly independent co-integration vectors (the dimension of $\mathbf{y}_{t}$ is k); second, co-integration variables must have the same integration order; third, the co-integration variables have a common trend component, and are proportional in terms of quantity; Fourth, co-integration relationship we usually refer to the co-integration relationship between the variables $(\mathrm{d}, \mathrm{d})$ [30].

The test for the bivariate co-integration relationship is usually performed by EG or AEG (Engel-Granger) test, which are co-integration tests based on regression residuals. We use the EG two-step co-integration test to determine the co-integration relationship between $\operatorname{lnGDP}$ and $\operatorname{lnVE}$. Since we have confirmed that the relationship between InGDP and $\operatorname{lnVE}$ is the integration of same order before, we can consider whether there is a co-integration relationship between them.

- Step 1: make the co-integration regression.

We intend to study the influence of $\operatorname{lnVE}$ on $\operatorname{lnGDP}$. So we make OLS regression to the long-term equilibrium equation $\ln G D P_{t}=a_{1}+b_{1} \ln V E_{t}+\delta_{t}$.

$$
\begin{gathered}
\ln G D P_{t}=8.9397+0.6740 \ln V E_{t} \\
\mathrm{t}: 43.745642 .2775 \\
\mathrm{P}:(0.0000)(0.0000) \\
R^{2}=0.9911 \mathrm{~F}=1787.388 \mathrm{DW}=1.0967
\end{gathered}
$$

The author preserves the residual $\mathrm{ecm}_{t}$ as an estimate of the equilibrium error $\delta_{t}$.

- Step 2: make stable test on the residual sequence.

For both co-integration variables, the equalization error must be stable. In order to test its stationarity, we can use EG method to make unit root test on the estimate $\mathrm{ecm}_{t}$ of equilibrium error stored in the previous step. Although the regression equation of the EG test is similar to the DF test, asymptotic distribution of the EG estimator of residual sequence is different from that of the incremental distribution of the DF statistic, which is located on the left side of the DF statistic distribution position, so it is necessary to find the critical value table of EG to determine whether the residual sequence is stable.

The results of EG test equation $\Delta e c m_{t}=\eta e c m_{t-1}+\mu_{t}$ by using the OLS method to estimate the residual sequence are as follows:

$$
\begin{gathered}
\Delta e c m_{t}=-0.7520 e c m_{t-1} \\
(-4.0435) \\
R^{2}=0.4990 \quad D W=1.1302
\end{gathered}
$$

TABLE III. CRITICAL VAlue TABle OF CO-INTEGRATION TEST EG OR AEG

\begin{tabular}{clll}
\hline Sample size & $\begin{array}{c}\text { Significance } \\
\text { level of } \mathbf{1 \%}\end{array}$ & $\begin{array}{c}\text { Significance } \\
\text { level of } \mathbf{5 \%}\end{array}$ & $\begin{array}{c}\text { Significance } \\
\text { level of } \mathbf{1 0 \%}\end{array}$ \\
\hline $\mathbf{2 5}$ & -4.37 & -3.59 & -3.22 \\
\hline $\mathbf{5 0}$ & -4.12 & -3.46 & -3.13 \\
\hline $\mathbf{1 0 0}$ & -4.01 & -3.39 & -3.09 \\
\hline
\end{tabular}

b. Note: The critical value of the EG or AEG stable test is related to the number of test variables. Here we select a part of the critical value of EG or AEG test with 2 variables.

The original hypothesis of the EP stable test is $H_{0}: \eta=0$ That is to say, the residual sequence is non-stable. As can be seen from "Table III", the larger the sample size is, the greater the critical value of the EG test at all significance level is. The sample size of this study is 18 , which is less than 25 , so when the sample size is 18 , the critical value at each significance level is less than that of the sample size of 25. It can be seen from the equation (5) that the statistic of the EG test of the residual sequence is -4.0435 . According to the above analysis, it can be seen that at least at the significance level of $10 \%(-3.22)$, we can absolutely reject the original hypothesis, which means the residual sequence is stable. Therefore, according to the co-integration equation, it can be concluded that there is a long-term stable codirectional relationship between vocational education and economic growth in Chongqing, namely the co-integration relationship with the same direction. 
3) Granger causality test: There is a causal relationship in the economic sense between the time variables with cointegration relations, but whether there is a significant causal relationship in statistics needs to be further tested by the Granger causality test. Granger causality tests the causal relationship in statistics, the idea is: whether $x$ can cause $y$ mainly depends on the extent to which the current $y$ can be explained by the past $y$, and whether adding the lag value of $x$ can increase the degree of interpretation. If it is helpful in the prediction, or if the correlation coefficient is statistically significant, it can be said that "it is caused by Granger" [30] 277. It can be seen that the Granger causality test is actually based on the VAR model, and the test model is:

$$
\begin{aligned}
& Y_{t}=\sum_{i=1}^{m} \alpha_{i} X_{t-i}+\sum_{i=1}^{m} \beta_{i} Y_{t-1}+\mu_{1 t} \\
& X_{t}=\sum_{i=1}^{m} \theta_{i} Y_{t-i}+\sum_{i=1}^{m} \delta_{i} X_{t-1}+\mu_{1 t}
\end{aligned}
$$

If the overall $\alpha$ is not zero, and the overall $\theta$ is zero, $\mathrm{X}$ has a one-way effect on $\mathrm{Y}$;

If the overall $\theta$ is not zero, and the overall $\alpha$ is zero, $\mathrm{Y}$ has a one-way effect on $\mathrm{X}$;

If the overall $\alpha$ and $\theta$ are not zero, there is a two-way effect between $\mathrm{X}$ and $\mathrm{Y}$;

If the overall $\alpha$ and $\theta$ are zero, there is no interplay between $\mathrm{X}$ and $\mathrm{Y}$;

Granger test is completed by the F-test that is restricted. Taking (8) as an example, the original hypothesis is $H_{0}$ : $\alpha_{1}=\alpha_{2} \cdots=\alpha_{n}$, and the test statistics are:

$$
F=\frac{\left(R S S_{R}-R S S_{U}\right) / m}{R S S_{U} /(n-k)}
$$

In the above equation, $\mathrm{RSS}_{\mathrm{R}}$ refers to the quadratic sum of regression residuals of the lagged variable that doesn't include $\mathrm{X}$ in the equation (6), while $\mathrm{RSS}_{\mathrm{U}}$ is the quadratic sum of regression residuals of the lagged variable that includes $\mathrm{X}$, and $\mathrm{m}$ is the number of the lagged variables of $\mathrm{X}$, $\mathrm{n}$ is the sample size, and $\mathrm{K}$ is the number of parameters to be estimated in the unconstrained regression model of equation (6) including constant term.

Since the Granger causality test is very sensitive to the lag order, it becomes the key to the validity of the test to choose the appropriate lag order. First, since the Granger causality test is based on the VAR model, the lag order of the Granger test model is the lag order of the corresponding VAR model. In this paper, we select the first order lag to carry out the Granger causality test. From the LM test that is related to the first order sequence of the stochastic disturbance of test model, it can be seen that the corresponding adjoint probability of the equation $\mathrm{LM}=$ 2.7048 with $\operatorname{lnGDP}$ as the explained variable is $\mathrm{P}=0.1000$, which shows that at the significance level of $10 \%$, the original hypothesis that there is no sequence correlation is accepted, so the equation has no sequence correlation. At the same time, the corresponding adjoint probability of LM = 0.0840 with $\operatorname{lnVE}$ as the explained variable is $\mathrm{P}=0.7720$, Indicating that the test model has no sequence correlation at the significance level of $10 \%$. Therefore, it is reliable for the test model to take the test results of first order lag.

Second, we have, through the perpetual inventory method, controlled the effect of vocational education on economic growth within the current year as much as possible in data processing phase. That is, through inventory, the current fixed asset investment that could have an impact on the economic growth of the later years is included in the later investment in vocational education, taking into account the impact of previous fixed assets stock and the current investment on current economic growth. Therefore, in the Granger causality test, we try to choose a relatively small lag order (Lags $=1$ ). Because economically speaking, after the inventory processing, lnVE lagging too much obviously has no effect on $\operatorname{lnGDP}$, it is also economically reasonable to choose 1 as the lag order.

According to the above analysis, the results of Granger

\begin{tabular}{|c|c|c|c|c|}
\hline $\begin{array}{c}\text { Original } \\
\text { hypothesis }\end{array}$ & Observations & F statistic & $P$ value & Conclusion \\
\hline $\begin{array}{l}\text { InGDP is not } \\
\text { the Granger } \\
\text { cause of InVE }\end{array}$ & 17 & 3.2003 & 0.0953 & $\begin{array}{l}\text { Economic } \\
\text { growth is } \\
\text { the Granger } \\
\text { cause of } \\
\text { vocational } \\
\text { education } \\
\text { development }\end{array}$ \\
\hline $\begin{array}{l}\text { LnVE is not } \\
\text { the Granger } \\
\text { cause of } \\
\text { lnGDP }\end{array}$ & 17 & 9.7843 & 0.0074 & $\begin{array}{l}\text { Vocational } \\
\text { education } \\
\text { development } \\
\text { is the } \\
\text { Granger } \\
\text { cause of } \\
\text { economic } \\
\text { growth }\end{array}$ \\
\hline
\end{tabular}
causality test on lnGDP and lnVE are shown in "Table IV"

TABLE IV. Granger CAUSALity Test $($ LAgS $=1)$

From the Granger causality test, it can be seen that the $\mathrm{P}$ value of the second original hypothesis is 0.0074 , which rejects the original hypothesis at the significance level of $1 \%$, so vocational education development is the Granger cause of economic growth. It can be seen that there is a significant causal relationship between the development of vocational education and economic growth in Chongqing.

4) Estimation and selection of error correction model: According to the above Granger causality test, we can establish ECM model to describe the facilitation of vocational education development to economic growth in Chongqing. The standard error correction model does not include the lagged variable of the explained variables, but considering the possible autocorrelation of the model, the lagged variable of the explained variables can be added to the model to eliminate the autocorrelation and obtain a better model. Whether the model should contain constant items also needs to be judged from the significance of 
various coefficients of regression results and the imitative effect of the equation. In order to get the optimal error correction model describing the relationship between economic growth and vocational education development in Chongqing, we estimate the following four model forms and select the optimal one:

$$
\begin{aligned}
& d \ln G D P_{t}=\beta d \ln V E_{t}+\gamma e c m_{t-1}+\varepsilon_{t} \\
& d \ln G D P_{t}=\alpha+\beta d \ln V E_{t}+\gamma e c m_{t-1}+\varepsilon_{t} \\
& d \ln G D P_{t}=\beta d \ln V E_{t}+\lambda d \ln G D P_{t-1}+\gamma e c m_{t-1}+\varepsilon_{t} \\
& d \ln G D P_{t}=\alpha+\beta d \ln V E_{t}+\lambda d \ln G D P_{t-1}+\gamma e c m_{t-1}+\varepsilon_{t}
\end{aligned}
$$

\begin{tabular}{|c|c|c|c|c|}
\hline $\begin{array}{c}\text { Coefficient } \\
\text { and } \\
\text { statistics }\end{array}$ & $\begin{array}{c}\text { Equation } \\
(9)\end{array}$ & $\begin{array}{c}\text { Equation } \\
\text { (10) }\end{array}$ & $\begin{array}{c}\text { Equation } \\
\text { (11) }\end{array}$ & $\begin{array}{c}\text { Equation } \\
\text { (12) }\end{array}$ \\
\hline$\alpha$ & - & $\begin{array}{l}0.0958 \\
(0.0018)\end{array}$ & - & $\begin{array}{l}0.0310 \\
(0.3819)\end{array}$ \\
\hline$\beta$ & $\begin{array}{l}0.5731 \\
(0.0000)\end{array}$ & $\begin{array}{l}0.1108 \\
(0.3981)\end{array}$ & $\begin{array}{l}0.2163 \\
(0.0171)\end{array}$ & $\begin{array}{l}0.1563 \\
(0.1573)\end{array}$ \\
\hline$\lambda$ & - & - & $\begin{array}{l}0.6536 \\
(0.0001)\end{array}$ & $\begin{array}{l}0.4999 \\
(0.0346)\end{array}$ \\
\hline$\gamma$ & $\begin{array}{l}-0.6825 \\
(0.0016)\end{array}$ & $\begin{array}{l}-0.3115 \\
(0.0736)\end{array}$ & $\begin{array}{l}-0.3685 \\
(0.0169)\end{array}$ & $\begin{array}{l}-0.2840 \\
(0.1097)\end{array}$ \\
\hline$R^{2}$ & $\begin{array}{l}-0.6020 \\
(0.7088)\end{array}$ & $\begin{array}{l}0.2190 \\
(0.1074)\end{array}$ & $\begin{array}{l}0.3404 \\
(0.2389)\end{array}$ & $\begin{array}{l}0.3827 \\
(0.2284)\end{array}$ \\
\hline$F$ & - & $\begin{array}{l}1.9624 \\
(0.1773)\end{array}$ & - & $\begin{array}{l}2.4802 \\
(0.1110)\end{array}$ \\
\hline$L M(1)$ & $\begin{array}{l}5.4844 \\
(0.0192)\end{array}$ & $\begin{array}{l}5.7290 \\
(0.0167)\end{array}$ & $\begin{array}{l}0.4692 \\
(0.4933)\end{array}$ & $\begin{array}{l}0.0912 \\
(0.7627)\end{array}$ \\
\hline
\end{tabular}

TABLE V. MOdel Estimation Results

c. Note: The values shown in the table are the coefficient values or the statistical values and the values in brackets are the $\mathrm{P}$ values for judging the corresponding coefficient or significance level of the statistical value. In the column $R^{2}$, the content in brackets is the adjusted $R^{2}$. This column contains the auto-correlative chi-squared statistic of the first order of test equation and the corresponding $\mathrm{P}$ value.

It can be seen from "Table $\mathrm{V}$ " that in the equation with lnGDP serving as explained variable, although the variable coefficient values of equation (9) and (10) are significant. However, according to LM (1), both equations have firstorder serial correlation, and the coefficient of determination of Equation (11) is negative, so the equations (9) and (10) are excluded. Similarly, according to the LM (1) test, we can see that there is no sequence correlation between equation (11) and equation (12), and by comparing the significance of the regression coefficients of the two equations, the equation (11) is better than the equation (12). Therefore, the error correction model with $\operatorname{lnGDP}$ as the explained variable should choose the form of equation (11).

The final estimating results of error correction model of vocational education development promoting economic growth in Chongqing are as follows:

$d \ln G D P_{t}=0.2163 d \ln V E_{t}+0.6536 d \ln G D P_{t-1}-0.3685 e c m_{t-1}$

$$
\begin{aligned}
& \text { t: } 2.7314 \quad 5.3219 \\
& -2.7390 \\
& \text { P: (0.0171) (0.0001) } \\
& \text { (0.0169) } \\
& R^{2}=0.3404 \quad \mathrm{LM}(1)=0.4692(\mathrm{P}=0.4933) \quad \mathrm{SE}=0.0261
\end{aligned}
$$

\section{Interpretation of Results of Error Correction Model}

The results of model estimation (13) show the long term and short term effects of vocational education development on economic growth in Chongqing. The fluctuation of explained variables in the model comes from two parts. Part of them are short-term fluctuations, which are expressed by the influence of the difference term in the model while another part is long-term equilibrium constraints, which are explained by the changes and adjustments of the error correction items in the model.

From the $t$ statistic of each coefficient and the corresponding $\mathrm{P}$ value, each coefficient has a very high significance, and then from the coefficient of determination and regression standard error it can be seen that the overall fitting of equation is better. The analysis of economic meaning is as follows: in the short term, every $1 \%$ increase in vocational education investment in Chongqing will drive the economic growth of Chongqing to increase by $0.2163 \%$, while in the long-term, every $1 \%$ change in vocational education in Chongqing will drive the economic growth of Chongqing to raise by $0.674 \%$ (Equation (4)), which indicates that the short-term effect of vocational education on economic growth of Chongqing is not obvious, while the long-term promotion is very obvious. This also reflects that education as the investment in a human capital will not immediately affect the result. Only when education is internalized as the knowledge, skills and labor proficiency of the labor force, the impact on output becomes significant. Therefore, the impact of vocational education on economic growth has time-lag and can only be manifested in the long term. When the deviation of investment in vocational education in Chongqing and economic growth maintains long-term equilibrium in the last period, the long-term equilibrium relationship between the two will haul back the disequilibrium to equilibrium with the intensity of (-0.3685).

\section{CONCLUSION}

\section{A. Conclusion}

Based on the above empirical analysis, it is concluded that the development of vocational education in Chongqing has a significant impact on economic growth. First, for the facts of coexistence of big countryside and big cities in Chongqing, the large proportion of rural population and the large number of poor people, the development of vocational education has played a positive role in promoting the economic growth of Chongqing and the peasants' poverty alleviation in northeast and southeast of Chongqing. Every $1 \%$ increase in long-term vocational education investment will drive the economic growth in Chongqing to increase by $0.674 \%$. Second, according to the adjustment coefficient of equation error, it can also be seen that the promotion of vocational education in Chongqing to economic growth is very stable (the adjustment coefficient is small). Third, the status of promotion role of vocational education to economic growth is that the long-term role is greater than the shortterm impact, showing that the impact of vocational education on economic growth can only be revealed in the long term. 


\section{B. Countermeasures and Suggestions}

1) Chongqing should increase investment in vocational education: Based on the current reality of excessive theoretical talent of higher education and the shortage of technology-based and skilled talents, Chongqing should strengthen the financial support for vocational education, and guide the social resources to incline to the vocational education. In the new normal of economic development, strengthening the investment in vocational education and training large quantities of high-quality professional talents can inject new vitality to transformation and upgrading of automobile manufacturing, financial services, electronic information and other pillar industries in Chongqing.

2) The development of vocational education in chongqing should pay attention to the reasonable industrial distribution: Under the new normal, according to the direction of industrial structure adjustment in Chongqing, they should reasonably arrange the professional setting of vocational colleges, gradually remove the majors that match the overcapacity and backward industries, and add the majors that adapt to the strategic emerging industry like electronic information, big data, Internet of things, and intelligent equipment, etc.

3) The development of vocational education in chongqing should pay attention to the reasonable regional distribution: The special economic geography environment of coexistence of big countryside and big cities in Chongqing indicates that inevitably there is nonequilibrium in the regional level in the economic development. That is, the northeast and southeastern part of Chongqing dominated by the rural areas receive less economic radiation of the metropolitan areas due to the distance, so economic development is bound to lag behind the metropolitan area containing main cities. Therefore, the higher vocational education should be distributed more in the northeastern and the southeastern region of Chongqing. Thus they can provide adequate personnel guarantee for northeast and southeast regions to form their own economic growth pole through educating and training high-skilled talent.

\section{REFERENCES}

[1] Liu Weiwei, An Heping. An Empirical Analysis of the Contribution of Vocational Education to Economic Growth in Hebei Province. Continue Education Research, 2010(2): 115-117.

[2] Li Ruihua. An Economic Study on Poverty and Anti-poverty: A Case Study of Inner Mongolia. Central Compilation \& Translation Press, 2014:31.

[3] Liu Wanxia. Human Capital Investment Structure and Regional Economic Growth - Enlightenment to the Development of Vocational Education. China Population, Resources and Environment, 2014,v.24;No.163(S1):235-238

[4] Feng Xiao, Zhu Yanyuan, Yang Qian. Research on Production Function of Chinese National Economy Based on Human Resource Distribution Variance. China Economic Quarterly, 2012,11(2):197232
[5] Qu Xiaochu, Zhu Xiaoyan. A Study on the Contribution Rate of Vocational Education to Regional Economy - Based on the Analysis of Guangdong and Hunan Provinces. Seeker, 2014(4):182-185.

[6] Denison E F. Why growth rates differ;postwar experience in nine western countries[J].Revue Économique,1967,20(5):915-917.

[7] Wang Lei. A Study on the Contribution of Vocational Education to Economic Growth - An Empirical Study Based on Provincial Panel Data. Journal of Central University of Finance \& Economics, 2011(8):80-85.

[8] Chung Y. The Contribution of Vocational and Technical Education to Economic Growth in Hong Kong[J].Chinese University Education Journal,1986,14(2):33-42.

[9] Vaughan R J. The New Limits to Growth: Economic Transformation and Vocational Education[J].Phi Delta Kappan,1991,72(6):446-449.

[10] Ashton D N, Green F. Education, training and the global economy [M]. Cheltenham: Edward Elgar, 1996:169-201.

[11] Self S, Grabowski R. Education and long-run development in Japan[J]. Journal of Asian Economics,2003,14(4):565-580.

[12] Mupimpila C, Narayana N. The role of vocational education and technical training in economic growth: a case of Botswana[J]. International Journal of Education Economics and Development,2009, 1(1):3-13.

[13] Nilsson A. Vocational Education and Training - An Engine for Economic Growth and a Vehicle for Social Inclusion? [J]. International Journal of Training \& Development, 2010, 14(4):251272 .

[14] Đuric',I,Đuric',D,ŽIvkovic'P.Secondary vocational education in service of economic growth and society development. [J].Economics of Agriculture,2013,60:759-773.

[15] Pillay H K, Ninan A. India's vocational education capacity to support the anticipated economic growth[J]. Queensland University of Technology, 2014

[16] Fu Zhiming, Xu Xiaoyan. Contribution Rate of Vocational Education in China to Economic Growth. Education and Vocation, 2005(13):16-17.

[17] Hang Yongbao. Classified calculation of Contribution of Chinese Education to Economic Growth and Its Correlation Analysis. Educational Research, 2007(2):38-47

[18] Yang yi, Tan Jiezhong. A Study on the calculation of Contribution Rate of Vocational Education to Economic Growth and Its Empirical Analysis. Education and Vocation, 2010(23):17-18

[19] Liu Xiaoming, Wang Jinming. An Empirical Analysis of the Contribution Rate of Higher Vocational Education to Economic Growth in Zhejiang Province. Chinese Vocational and Technical Education, 2011(18):36-40

[20] Guo Xinhua, Yu Xiaoyue. Contribution of Secondary Vocational Education to Economic Growth in China: 1985-2007. Science Economy Society, 2010 28(3):33-36.

[21] Wang Peijun, Wang Liping. The Influence of Chinese Vocational Education on Economic Growth. Vocational and Technical Education, 2011,32(16):24-28

[22] Zhou Hong, Yang Mengmeng, Wang Tingting. The Impact of Secondary Vocational Education on Economic Growth in China Based on Provincial Panel Data from 2003 to 2008 Public Finance Research, 2012(2):53-55.

[23] Wang Haiyan, Shen Youlu. An Empirical Study on the Relationship between Secondary Vocational Education and Economic Growth in Western China - Based on Empirical Data of China from 1990 to 2009. Vocational and Technical Education, 2012,33(1):48-52.

[24] Yang Yong, Ning rui, Qi Xugao. An Empirical Analysis on the Contribution Rate of the scale of Higher Vocational Education in China to Economic Growth. Chinese Vocational and Technical Education, 2016(9):9-14.

[25] Li Changhui, Xiang Caiyi, Ma Shizhou, et al. A Study on the Contribution of Secondary Vocational Education to Economic Development - Taking Chongqing as an Example. Probe, 2008(1):186-191. 
[26] Hu Jiangxia, Luo Yulong, Zheng Hongwei. Gray Relational Analysis of Investment in Vocational Education and Regional Economic Growth - Based on the Data of Chongqing. Education Research Monthly, 2013(10).

[27] Xu Ling. An Empirical Study on the Relationship between the Scale of Higher Vocational Education and Economic Growth in China Based on the Data Analysis from 1992 to 2010. Higher Education Exploration, 2013(5):135-138.

[28] Shan Haojie. Re-estimation of China's Capital: 1952- 2006. The Journal of Quantitative \& Technical Economics, 2008 (10):17-31

[29] Gao Tiemei. Econometric Analysis Methods and Modeling: EViews Applications and Examples - 2nd Edition. Tsinghua University Press, 2009.

[30] Li Zinai, Pan Wenqing. Econometrics (Third edition). Higher Education Press, 2002:175. 